
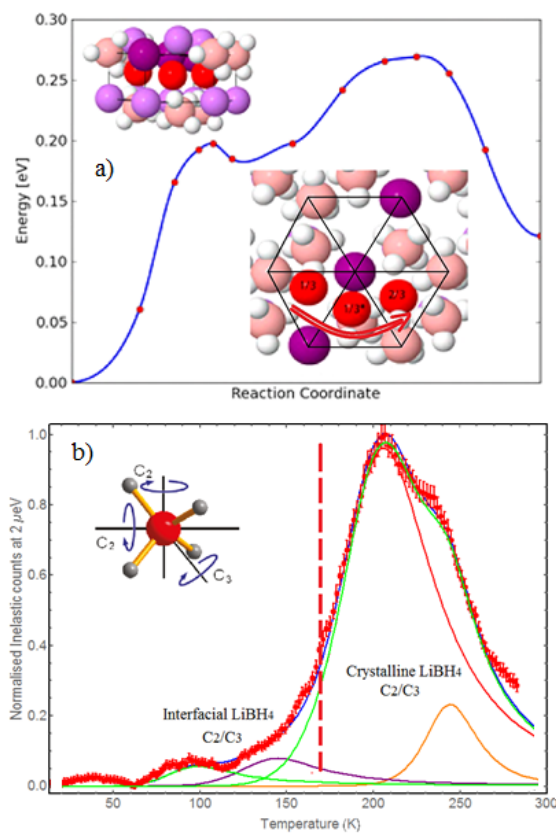

Figure 1. a) DFT energy path for interstitial Li diffusion. b) $\mathrm{LiBH}_{4} / \mathrm{SiO}_{2}$ neutron inelastic temperature scans. The four quasi-elastic components correspond to reorientational diffusion of the $\mathrm{BH}_{4}{ }^{-}$along the $\mathrm{C}_{2}-\mathrm{C}_{3}$ axis for the interfacial $\mathrm{LiBH}_{4}$ (low temp.) and crystalline $\mathrm{LiBH}_{4}^{3}$ ( high temp.).

Keywords: Battery, Quasi-elastic Neutron Scattering, Density Functional Theory, all-solid-sate battery, solid electrolyte

\section{MS19-04 Characterization of cation ordering, oxygen vacancy distribution and proton sites in hexagonal and cubic$$
\mathrm{BaTi}_{1-\mathrm{x}} \mathrm{Sc}_{\mathrm{x}} \mathrm{O}_{3-\delta}
$$

Paul F. Henry ${ }^{1,2}$, Nico Torino ${ }^{2}$, Habibur S.M. Rahman ${ }^{2}$, Christopher S. Knee ${ }^{2}$, Sten G. Eriksson ${ }^{2}$, Stefan T. Norberg ${ }^{2}$, Tor S. Bjørheim ${ }^{3}$, Reidar Haugsrud ${ }^{3}$, Sam Callear ${ }^{4}$, Ron Smith ${ }^{4}$

1. European Spallation Source ERIC, Lund, Sweden

2. Chalmers University of Technology, Gothenburg, Sweden

3. University of Oslo, Norway

4. STFC, Didcot, UK

email: paul.henry@esss.se

Proton conducting oxides find applications as electrolyte materials in fuel cells, steam electrolysers and hydrogen and humidity sensors. Proton conducting fuel cells, which use $\mathrm{H}_{2}$ as a fuel, stand out as a promising technology for future clean energy generation. However, its success relies on the discovery of novel electrolyte materials with high protonic conduction at intermediate temperatures $\left(200-600^{\circ} \mathrm{C}\right)$. Acceptor doped perovskites are actively studied in the search for improved proton conducting materials. We have synthesized and characterized the proton conducting properties of the series $\mathrm{BaTi}_{1-\mathrm{x}} \mathrm{Sc}_{\mathrm{x}} \mathrm{O}_{3-\delta}(0.1 \leq \mathrm{x} \leq 0.8)$. [1,2] The series shows a transition from a $6 \mathrm{H}$ perovskite structure at low scandium doping to a cubic phase for $x \geq 0.5$. All the doped series show hydration behavior indicative of filling oxide ion vacancies within the structure and that protons are the dominant charge carriers below $600{ }^{\circ} \mathrm{C}$. The conductivity of the materials with the $6 \mathrm{H}$ structure is significantly lower than those with the cubic structure. $\mathrm{X}$-ray data suggest different oxygen vacancy ordering within the $6 \mathrm{H}$ perovskite structure at low doping levels, whereas the vacancies are distributed randomly in the cubic structure with no evidence of long range ordering of the $\mathrm{Ti}$ and $\mathrm{Sc}$ ions on the B-site. However, due to the weak scattering from oxygen $c f$. the transition metals and barium, coupled with the similar scattering power of the $\mathrm{Ti}$ and $\mathrm{Sc}$, the presence of cation and/or oxygen ion order and the driving force for the phase transition to the cubic structure are unknown. Moreover, the origin of the poorer conductivity of the $6 \mathrm{H} c f$. the cubic structure upon hydration is also unknown and is likely related to the proton sites and the exchange pathways within the material. Neutron powder diffraction (NPD) and recent in situ studies using combined NPD/thermogravimetric analysis resolving these key questions will be presented and coupled to DFT calculations.

[1] S.M.H Rahman, I. Ahmed, R. Haugsrud, S.G. Eriksson, C.S. Knee. (2014) Solid State Ionics, 255 , 140-146.

[2] S.M.H. Rahman, S.T. Norberg, C.S. Knee, J.J. Biendicho, S. Hull, S.G. Eriksson, (2014) Dalton Transactions, 43, 15055.

Keywords: neutron, powder diffraction, structure 